${ }^{1}$ School of Dentistry, University of Passo Fundo, Passo Fundo, Rio Grande do Sul, Brazil.

${ }^{2}$ Federal University of Pelotas, Pelotas, Rio Grande do Sul, Brazil.

${ }^{3}$ Federal University of Rio Grande do Sul. Porto Alegre, Rio Grande do Sul, Brazil.
Corresponding author: Francisco Wilker Mustafa Gomes Muniz. Federal University of Pelotas Rua Gonçalves Chaves, 457, Pelotas/RS, Brazil, ZIP Code: 960105-560. Phone/ Fax: +55 53 991253611. Email: wilkermustafa@gmail.com

Received: April 23, 2020

Accepted: August 02, 2020

\section{Concern with dental appearance and associated factors among the elderly of two southern Brazilian cities: a cross-sectional study}

\author{
Diandra Genoveva Sachetti ${ }^{1}$ iD, Fernanda Pretto \\ Zatt ${ }^{1}$, Thais Carleso Trevizan ${ }^{1}$, Caroline Fernandes e \\ Silva², Francisco Wilker Mustafa Gomes Muniz 2,* iD, \\ Cassiano Kuchenbecker Rösing ${ }^{3}$ (iD, Paulo Roberto \\ Grafitti Colussi ${ }^{1}$
}

Aim: This study aimed to evaluate the prevalence of concern with dental appearance (DA) and associated factors among the elderly of two southern Brazilian cities. Methods: A cross-sectional study was conducted in the cities of CruzAlta and Veranópolis, Brazil. Oral health examination and a structured questionnaire were applied. Questions from the PCATool-SB Brasil tool and the Questionnaire about Teeth Appearance, both validated to Brazilian samples, were used. The collected independent variables were: sex, age, ethnicity, education level, marital status, retirement, health problem, use of medication, smoking exposure, alcohol exposure, access to the dentist, toothbrushing frequency, use of dental floss, edentulism, use of and need for dental prosthesis. Concern with DA was dichotomized into yes/no. Associations between dependent and independent variables were assessed by Chi-square or MannWhitney tests. Moreover, uni- and multivariate analyses were conducted by Poisson regression with robust variance. Level of significance was established as $p<0.05$. Results: The prevalence of concern with DA was $18.8 \%(n=107)$. The prevalence ratio (PR) of concern with DA decreased $5.8 \%$ for each year increase (PR:0.942; 95\% confidence interval [95\%Cll]:0.911-0.973). Elderly without access to the dentist in the last 12 months presented $62.5 \%(p=0.006)$ higher PR of concern with DA when compared to those with access to dental care. Dentate elderly showed 219\% higher PR for concern with DA (PR:2.197; 95\%Cl:1.364-3.539) in comparison to edentulous individuals. Conclusion: Prevalence of concern with DA was low and associated with demographics, access to dental care and edentulism.

Keywords: Dental care for aged. Epidemiology. Esthetic, dental. Jaw, edentulous. Self concept. 


\section{Introduction}

The phenomenon of human aging is a reality, and reflects an intense demographic challenge, probably one of the largest in recent decades. According to this reality, there is need to provide a higher quality of life for these individuals, which includes better physical, social, and psychological aspects ${ }^{1}$. Regarding oral health in the elderly, the literature is consistent, demonstrating that these individuals have high rates of periodontal disease and tooth loss 2,3 .

Historically, dental services and public policies did not prioritize oral health care in the elderly ${ }^{4}$. This may be one of the explanations for the worse oral health condition in this population ${ }^{5}$. Those aspects are more evident in underdeveloped countries, such as Brazil, where mean number of lost teeth is higher and there is a high prevalence of edentulism6 ${ }^{6}$. Moreover, data from the latest national survey showed that most Brazilian elderly need prosthetic rehabilitation?. This impairs functional aspects, such as chewing and speaking, influencing aesthetics.

However, issues involving dental aesthetics still seem to be of minor importance to the elderly population. Studies demonstrate that less than $20 \%$ of the elderly report to be unsatisfied with dental appearance ${ }^{8,9}$. However, the literature indicates that greater satisfaction with oral appearance is a protective factor for the decline in some domains of quality of life $^{10}$. Additionally, there is a high perception of dental treatment needs and rehabilitation among the elderly ${ }^{11}$. Nevertheless, questions involving human aging and oral health, as well as their psychosocial consequences, need further understanding in the literature.

Currently, aspects related to elderly aesthetics are receiving more attention, mainly related to oral rehabilitation needs ${ }^{12}$. In contrast, knowledge about the elderly oral aesthetic self-perception is scarce in the literature. The present study aimed to evaluate the prevalence and associated factors of concern with dental appearance among the elderly, in two cities of the state of Rio Grande do Sul, Brazil. The null hypothesis of this study is that there are no significant associations between concern with dental appearance and demographic, socioeconomic and dental variables.

\section{Material and Methods}

\section{Study Design and Location}

This study followed is reported according to the STROBE checklist guidelines. Elderly aged $\geq 60$ years from two cities in the state of Rio Grande do Sul, Brazil were interviewed and examined in this cross-sectional study. The cities of Cruz Alta and Veranópolis are located in the north of Rio Grande do Sul state, approximately 350 and $160 \mathrm{~km}$ from the capital Porto Alegre, respectively. The population of Cruz Alta is approximately 62,821 inhabitants, while the population of Veranópolis is approximately 22,810 inhabitants $^{13}$. About $95 \%$ and $87 \%$ of the population live in the urban area, respectively, and, in both cities, around $60 \%$ of the elderly are female. The Municipal Human Development Index of Veranópolis, in 2010, was $0.75^{14}$, and the Gini Index, in the same year, was 0.4836, whereas these data, in Cruz Alta, were 0.75 and 0.5419, 
respectively ${ }^{15}$. For each city, two distinct research protocols were developed, reviewed and approved by the Ethical Committee of the University of Passo Fundo (protocol numbers $1,531,862$ and 2,990,088). All participants read and signed the informed consent form before their inclusion in the study.

\section{Sample Size Calculation}

Sample calculation was based on the elderly oral health self-perception prevalence reported in another study ${ }^{16}$. When assuming a prevalence of $31.92 \%$ of poor oral health self-perception, an alpha error of 5\%, a confidence interval of $99 \%$ and a population size of 7,284, a sample of 535 elderly people was considered necessary. An attrition rate of $5 \%$ was added.

\section{Sampling Strategy}

To be representative of both cities, different sampling strategies for the cities of Cruz Alta and Veranópolis were developed. In Cruz Alta, a per cluster probabilistic sample was conducted. Due to the high number of individuals in the urban area, only the elderly living in this area were included. The city of Cruz Alta has 68 district or neighborhoods, which were listed and received a number. Of these, seventeen were randomly selected (25\%), through the website www.random.org, considering the proportion of elderly residents in the area. More information about the sampling strategy in Cruz Alta city can be found elsewhere ${ }^{17}$.

For the city of Veranópolis, another probabilistic sample by cluster was performed to visit 300 residences, respecting the proportion of urban and rural areas. Based on the city urban area map, all blocks were numbered. A total of 82 blocks (20\% of the total blocks) were randomly selected in this area, using the website www.random. org. Additionally, the blocks corners were numbered from one to four, and a new draw was conducted to determine the first interview. In each block, three households with at least one resident elderly were visited. After the first interview, the visits continued in a clockwise direction until complete the planned work. Whenever necessary, new blocks were selected in order to include the necessary number of households.

In Veranópolis, a total of three rural communities were part of the study, randomly selected using the website www.random.org, among all 21 rural communities in the city. Households were visited until reaching at least 12 elderly people interviewed and examined in each community. Rural area households involved residences in the central nucleus of the community and others located along the several community side roads.

\section{Inclusion and Exclusion Criteria}

Individuals to be included in the present study should be at least 60 years old and living in the selected households in the sampling strategy. Participants that answered all questions and allowed the clinical oral examinations were included in the present study. If more than one elderly person met the eligibility criteria, in each residence, all of them were included. In the case of absence on the day of data collection, two more attempts were made before excluding the household. Homes for the aged (i.e. geriatric long-term care facilities), stores, elderly who were visiting the selected area and uninhabited homes were not included. 


\section{Clinical Examination and Interview}

Elderly were interviewed between July and August 2016, in Cruz Alta, and between December 2018 and January 2019, in Veranópolis. In both cities, the same structured questionnaire, which included socio-demographic, behavioral, medical and dental history data, was applied. These variables were obtained by the question blocks from the PCATool-SB Brasil tool ${ }^{18}$. The complete questionnaire may be found elsewhere ${ }^{19}$. The questions related to concern with dental appearance and dental aesthetic perception were obtained by the Questionnaire about Teeth Appearance, a validated questionnaire for the Brazilian population ${ }^{20}$. Oral health was assessed by counting teeth and verifying use and need for dental prosthesis, according to the World Health Organization criteria ${ }^{21}$. Oral examinations were performed with a wooden spatula, without artificial lighting or odontoscope.

Individuals were examined and interviewed by teams composed of an interviewer and an oral health examiner, who were previously trained by the study coordinators to ensure uniformity of data. Training consisted of lectures, discussion of all the questions in the questionnaire and explanations about oral health examination. The same coordinator was responsible for all teams in both cities. Before the study, training was conducted with the questionnaire application and with the oral health exam in elderly patients undergoing treatment in the School of Dentistry of the University of Passo Fundo clinics. The intra- and inter-examiner reproducibility of the clinical oral health examination was verified in 5\% of the total population. After 14 days, the examination was repeated. When considering all the examiners, the inter- and intra-examiner reproducibility demonstrated a kappa index of at least 0.70 for all variables.

\section{Statistical Analysis}

The dependent variable of the present study was concern with dental appearance determined by a validated instrument ${ }^{20}$. The question used was: "During the past two months, how much did your teeth appearance concern you"? The options of answers were: a lot, a little, very little, nothing and I do not know. The sample was categorized into two groups, those who answered "very little", "nothing" or "I don't know" were included in the group that was not concerned about their teeth appearance. Those who answered "a lot" or "a little" were included in the group that was concerned about their teeth appearance. Gender, age, ethnicity/skin color, educational level, marital status, retirement, health problems, use of medication, exposure to smoking and alcohol, access to the dentist in the last 12 months, frequency of toothbrushing, flossing, edentulism, use of prosthesis, need for prosthesis were considered independent variables in the present study.

Age was recorded in years, and sex, as male or female. Ethnicity/skin color was classified as white or non-white (the non-white classification included elderly people who referred themselves as black, yellow, brown or indigenous). Level of education was classified as low, which included illiterate participants and those with incomplete or complete elementary school; medium, for those with incomplete or complete high school; and high level, for those with at least incomplete college/university degrees. Marital status was classified as married or not married. The not married group was composed of those who reported being single, divorced or widowed. Regarding retirement, the elderly were dichotomized into retired and not retired. 
Regarding general health conditions, the elderly were classified into two groups: one that involved individuals with no health problems or who were not aware of having them, and those who reported having some type of health problem. Use of medication was classified into two groups: one with participants who reported using one or more medications, and another group who did not reported use of medication. Smoking exposure was classified into three groups: no history of smoking, current smokers and former smokers. Alcohol exposure was classified into yes or not. Those who reported consuming alcohol frequently or moderately were considered as alcohol users, and the other individuals were considered as non-users.

Access to the dentist in the last 12 months and the use of dental floss use were dichotomized as yes or not. Toothbrushing frequency was classified into two groups: at least once a day and twice or more a day. Elderly that used any dental prosthesis in at least one arch were included in the group that uses dental prosthesis. Similarly, the elderly that needed oral rehabilitation in at least one arch were included the in the group that needs dental prosthesis. These criteria were used based on the World Health Organization for epidemiologic studies on oral health ${ }^{20}$. Tooth loss was categorized as edentulism, for those without any teeth, and non-edentulism, for those with one or more teeth.

Associations between dependent and independent variables were assessed through Chi-square or Mann-Whitney tests. Additionally, uni- and multivariate analyses were performed by Poisson regression with robust variance to verify associations between independent variables and concern with dental appearance. In the multivariate model, the variables that presented $p<0.20$ in univariate analysis were included. The maintenance of these variables, in the final multivariate model, was determined by the combination of $p<0.05$ and changing effect models analysis. Moreover, multicollinearity analyses were performed and none was observed.

\section{Results}

A total of 569 individuals were interviewed and examined, of which 287 were from Cruz Alta and 282 were from Veranópolis. In the present sample, mean ( \pm standard deviation) age was $70.35 \pm 6.18$, with $67.8 \%(n=386)$ of female individuals. The majority of the included elderly considered themselves to be white $(78.7 \%, n=448)$, had a low educational level $(72.9 \%, n=415)$, were retired $(82.2 \%, n=468)$, and $55.4 \%(n=315)$ of them were married. The prevalence of concern with dental appearance was $18.8 \%$ $(n=107)$. Age, edentulism and need for dental prosthesis were significantly associated with concern with dental appearance (Table 1).

In Table 2, univariate analysis of the association between concern with dental appearance and the exploratory variables is shown. Age, smoking exposure, edentulism, use of dental prosthesis and need for dental prosthesis were associated with concern with dental appearance. In this model, by each additional year of age, there was a $7 \%$ decrease $(p<0.001)$ in the Prevalence Ratio $(P R)$ of the elderly being concerned with their dental appearance. Elderly with no history of smoking had $42.7 \%$ lower PR of concern with dental appearance when compared to elderly that currently smoke. Dentate elderly had approximately 2.5 times higher PR of concern about their teeth appearance when compared with edentulous elderly $(p<0.001)$. Those that did not 
Table 1. Demographic, behavioral, medical, and dental variables according to concern with dental appearance.

\begin{tabular}{|c|c|c|c|c|}
\hline Variables & $\mathrm{n}-(\%)$ or mean $\pm \mathrm{SD}$ & $\begin{array}{c}\text { Concerned } \\
(n=462 ; 81.2 \%)\end{array}$ & $\begin{array}{l}\text { Not concerned } \\
(n=107 ; 18.8 \%)\end{array}$ & p-value \\
\hline Sex & $\begin{array}{l}\text { Male } \\
\text { Female }\end{array}$ & $\begin{array}{l}150(32.5) \\
312(67.5)\end{array}$ & $\begin{array}{l}33(30.8) \\
74(69.2)\end{array}$ & $0.819 *$ \\
\hline Age & & $70.87 \pm 6.39$ & $68.09 \pm 4.57$ & $<0.001 \#$ \\
\hline Ethnicity/skin color & $\begin{array}{c}\text { White } \\
\text { Non-white }\end{array}$ & $\begin{array}{c}369(79.9) \\
93(20.1)\end{array}$ & $\begin{array}{l}79(73.8) \\
28(26.2)\end{array}$ & $0.190 *$ \\
\hline Education level & $\begin{array}{l}\text { Low } \\
\text { Medium } \\
\text { High }\end{array}$ & $\begin{array}{c}341(73.8) \\
65(14.1) \\
56(12.1)\end{array}$ & $\begin{array}{l}74(69.2) \\
22(20.6) \\
11(10.3)\end{array}$ & $0.234^{*}$ \\
\hline Marital status & $\begin{array}{c}\text { Married } \\
\text { Not married }\end{array}$ & $\begin{array}{l}253(54.8) \\
209(45.2)\end{array}$ & $\begin{array}{l}62(57.9) \\
45(42.1)\end{array}$ & $0.590 *$ \\
\hline Retirement & $\begin{array}{l}\text { Yes } \\
\text { No }\end{array}$ & $\begin{array}{l}380(82.3) \\
82(17.7)\end{array}$ & $\begin{array}{l}88(82.2) \\
19(17.8)\end{array}$ & $1.000 *$ \\
\hline Health problem & $\begin{array}{l}\text { Yes } \\
\text { No }\end{array}$ & $\begin{array}{c}404(87.4) \\
58(12.6)\end{array}$ & $\begin{array}{l}92(86.0) \\
15(14.0)\end{array}$ & $0.748^{*}$ \\
\hline Use of medication & $\begin{array}{l}\text { Yes } \\
\text { No }\end{array}$ & $\begin{array}{c}392(84.8) \\
70(15.2)\end{array}$ & $\begin{array}{l}90(84.1) \\
17(15.9)\end{array}$ & $0.882^{*}$ \\
\hline Smoking exposure & $\begin{array}{c}\text { Smokers } \\
\text { Ex-smokers } \\
\text { Never smokers }\end{array}$ & $\begin{array}{c}39(8.4) \\
123(26.6) \\
300(64.9)\end{array}$ & $\begin{array}{l}16(15.0) \\
31(29.0) \\
60(56.1)\end{array}$ & $0.079 *$ \\
\hline Alcohol exposure & $\begin{array}{l}\text { Yes } \\
\text { No }\end{array}$ & $\begin{array}{l}220(47.6) \\
242(52.4)\end{array}$ & $\begin{array}{l}46(43.0) \\
61(57.0)\end{array}$ & $0.392^{*}$ \\
\hline Access to the dentist & $\begin{array}{l}\text { Yes } \\
\text { No }\end{array}$ & $\begin{array}{l}222(48.1) \\
240(51.9)\end{array}$ & $\begin{array}{l}44(41.1) \\
63(58.9)\end{array}$ & $0.199 *$ \\
\hline Tooth brushing frequency & $\begin{array}{l}<2 / \text { day } \\
\geq 2 / \text { day }\end{array}$ & $\begin{array}{c}44(9.5) \\
418(90.5)\end{array}$ & $\begin{array}{l}12(11.2) \\
95(88.8)\end{array}$ & $0.591^{*}$ \\
\hline Dental floss use & $\begin{array}{l}\text { Yes } \\
\text { No }\end{array}$ & $\begin{array}{l}129(27.9) \\
333(72.1)\end{array}$ & $\begin{array}{l}37(34.6) \\
70(65.4)\end{array}$ & $0.194^{*}$ \\
\hline Edentulism & $\begin{array}{l}\text { Yes } \\
\text { No }\end{array}$ & $\begin{array}{l}201(43.5) \\
261(56.5)\end{array}$ & $\begin{array}{l}22(20.6) \\
85(79.4)\end{array}$ & $<0.001^{\star}$ \\
\hline Use of dental prosthesis & $\begin{array}{l}\text { Yes } \\
\text { No }\end{array}$ & $\begin{array}{c}401(86.8) \\
61(13.2) \\
\end{array}$ & $\begin{array}{l}85(79.4) \\
22(20.6) \\
\end{array}$ & $0.067 *$ \\
\hline Need for dental prosthesis & $\begin{array}{l}\text { Yes } \\
\text { No }\end{array}$ & $\begin{array}{l}144(31.2) \\
318(68.8)\end{array}$ & $\begin{array}{l}54(50.5) \\
53(49.5)\end{array}$ & $<0.001$ * \\
\hline
\end{tabular}

Legend: *Qui-square; \#Mann-Whitney

use dental prosthesis had $51.6 \%$ higher PR of concern with dental appearance when compared to those that use. The elderly without need of oral rehabilitation with prosthesis had $47.6 \%$ ( $p<0.001)$ lower PR of concern about their teeth appearance when compared to elderly that needed dental prosthesis.

In addition to the already mentioned variables, ethnicity/skin color, education, access to the dentist, and use of dental floss were included in the initial multivariate model. Table 3 shows the final multivariate analysis associating concern with dental appearance and the independent variables. Age, access to the dentist in the last 12 months and edentulism remained associated. By each additional year of age, there was a $5.8 \%$ decrease in the PR of the elderly being concerned with their dental appearance (PR: 0.942; 95\% confidence interval; 95\% Cl: 0.911 - 0.973). The elderly lacking access to the dentist in the last 12 months had $62.5 \%(p=0.006)$ higher PR of concern with 
Table 2. Univariate analysis of the association of concern with dental appearance and sociodemographic variables, medical and dental histories.

\begin{tabular}{|c|c|c|c|}
\hline Variables & & Prevalence ratio ( $\mathrm{Cl} 95 \%)$ & p-value \\
\hline Sex & $\begin{array}{l}\text { Male } \\
\text { Female }\end{array}$ & $\begin{array}{c}\text { Ref. } \\
1.063(0.734-1.540)\end{array}$ & 0.746 \\
\hline Age & & $0.930(0.901-0.959)$ & $<0.001$ \\
\hline Ethnicity/skin color & $\begin{array}{c}\text { White } \\
\text { Non-white }\end{array}$ & $\begin{array}{c}\text { Ref. } \\
1.312(0.896-1.922)\end{array}$ & 0163 \\
\hline Education level & $\begin{array}{l}\text { Low } \\
\text { Medium } \\
\text { High }\end{array}$ & $\begin{array}{c}\text { Ref. } \\
1.418(0.935-2.150) \\
0.921(0.516-1.642)\end{array}$ & $\begin{array}{l}0.100 \\
0.780\end{array}$ \\
\hline Marital status & $\begin{array}{c}\text { Married } \\
\text { Not married }\end{array}$ & $\begin{array}{c}\text { Ref. } \\
0.900(0.637-1.273)\end{array}$ & 0.552 \\
\hline Retirement & $\begin{array}{l}\text { Yes } \\
\text { No }\end{array}$ & $\begin{array}{c}\text { Ref. } \\
1.000(0.639-1.563)\end{array}$ & 0.998 \\
\hline Health problem & $\begin{array}{l}\text { Yes } \\
\text { No }\end{array}$ & $\begin{array}{c}\text { Ref. } \\
1.108(0.680-1.803) \\
\end{array}$ & 0.681 \\
\hline Use of medication & $\begin{array}{l}\text { Yes } \\
\text { No }\end{array}$ & $\begin{array}{c}\text { Ref. } \\
1.046(0.657-1.667) \\
\end{array}$ & 0.848 \\
\hline Smoking exposure & $\begin{array}{c}\text { Smokers } \\
\text { Ex-smokers } \\
\text { Never smokers }\end{array}$ & $\begin{array}{c}\text { Ref. } \\
0.692(0.412-1.163) \\
0.573(0.357-0.919)\end{array}$ & $\begin{array}{l}0.164 \\
0.021\end{array}$ \\
\hline Alcohol exposure & $\begin{array}{l}\text { Yes } \\
\text { No }\end{array}$ & $\begin{array}{c}\text { Ref. } \\
1.164(0.824-1.645)\end{array}$ & 0.389 \\
\hline Access to the dentist & $\begin{array}{l}\text { Yes } \\
\text { No }\end{array}$ & $\begin{array}{c}\text { Ref. } \\
1.257(0.887-1.780)\end{array}$ & 0.198 \\
\hline Tooth brushing frequency & $\begin{array}{l}<2 / \text { day } \\
\geq 2 / \text { day }\end{array}$ & $\begin{array}{c}\text { Ref. } \\
0.864(0.507-1.473)\end{array}$ & 0.592 \\
\hline Use of dental floss & $\begin{array}{l}\text { Yes } \\
\text { No }\end{array}$ & $\begin{array}{c}\text { Ref. } \\
0.779(0.546-1.111)\end{array}$ & 0.169 \\
\hline Edentulism & $\begin{array}{l}\text { Yes } \\
\text { No }\end{array}$ & $\begin{array}{c}\text { Ref. } \\
2.490(1.608-3.857)\end{array}$ & $<0.001$ \\
\hline Use of dental prosthesis & $\begin{array}{l}\text { Yes } \\
\text { No }\end{array}$ & $\begin{array}{c}\text { Ref. } \\
1.516(1.009-2.277) \\
\end{array}$ & 0.045 \\
\hline Need for dental prosthesis & $\begin{array}{l}\text { Yes } \\
\text { No }\end{array}$ & $\begin{array}{c}\text { Ref. } \\
0.524(0.374-0.734)\end{array}$ & $<0.001$ \\
\hline
\end{tabular}

Table 3. Multivariate analysis of the association of concern with dental appearance and sociodemographic variables, medical and dental histories.

\begin{tabular}{lccc}
\hline Variables & & Prevalence ratio (Cl 95\%) & p-value \\
\hline Age & & $0.942(0.911-0.973)$ & 0.017 \\
Smoking exposure & $\begin{array}{c}\text { Smokers } \\
\text { Ex-smokers } \\
\text { Non smokers }\end{array}$ & $\begin{array}{c}\text { Ref. } \\
0.657(0.409-1.055)\end{array}$ & 0.268 \\
& Yes & Ref. & 0.082 \\
Access to the dentist & No & $1.625(1.150-2.297)$ & 0.006 \\
\hline \multirow{2}{*}{ Edentulism } & Yes & Ref. & 0.001 \\
\hline \multirow{2}{*}{ Use of dental prosthesis } & No & $2.197(1.364-3.539)$ & 0.999 \\
\hline Need for dental prosthesis & Yes & $1.000(0.656-1.523)$ & 0.173 \\
\hline
\end{tabular}


dental appearance when compared to ones with access to dental care. Moreover, dentate had approximately 2.2 times higher PR of concern with dental appearance (PR: 2.197; 95\% Cl: 1.364 - 3.539) when compared with edentulous individuals.

\section{Discussion}

The present study aimed to assess the prevalence of concern with dental appearance and associated factors in the elderly of two cities in South Brazil. The analysis merged data from two similar cities in order to increase observations and better support the analytical approach. In this particular population, concern with dental appearance was low and associated with age, access to the dentist and edentulism. Studies focusing on dental aesthetics among the elderly have increased, as their interaction with society has increased in recent decades, as well as due to aging of the populations ${ }^{22}$. Several aspects, such as greater social interactions, professional activities and the desire to enjoy life, require better health conditions of these individuals, including oral health. Oral aesthetics at this age group should receive attention especially due to the fact that satisfaction with dental appearance is often related to the general appearance, well-being, social interaction, self-esteem, and ultimately, quality of life 23,24 .

In the present study, the prevalence of concern with dental appearance was $18.8 \%$. This demonstrates that the percentage of elderly dissatisfied with their dental appearance is somewhat low. However, the percentage of concerns with dental appearance in the elderly seems to be slightly higher than those found in other studies, as published studies show estimates of dissatisfaction of $11 \%{ }^{25}, 12 \%$ and $13 \%{ }^{8}$. It is important to highlight that some differences between the findings of the present study and the other studies reported in the literature may be detected, which include the country in which they were performed. Most of them were performed in European countries and did not evaluate the percentage of edentulism and its impact on appearance perception. Moreover, the presence of edentulism and use of dental prosthesis were not assessed in those studies, which is a strength of the present study. Also, another possible explanation for such difference is the fact that those studies were performed more than five years ago and, with time, there is change in health tendencies, probably including oral health. In this sense, it is speculated that concern with dental appearance in the elderly will increase in the coming years.

The percentage of concern with dental appearance in the present study can be justified by the appearance acceptance process that seems to occur when one gets older. However, appearance investments should be considered more and more to maintain successful aging ${ }^{26}$. Therefore, the relationship between human aging and aesthetics may increase in the coming years, which warrants epidemiological studies and the development of appropriate assessment instruments for this age group ${ }^{24}$. Elderly in the work forces, the greater social interaction and use of social media can be situations involved in this process.

Important factors have been identified as potential influencers in body image construction and acceptance, including age. In the present study, age was associated with lower concern with oral aesthetics. In fact, by each additional age year, there was a 5.8\% decrease in the PR of the elderly being concerned about their smile appearance. It should 
be put into perspective that this decrease with aging is among elderly and not related to whole adulthood. These results corroborate with studies that demonstrate that aesthetics concern tends to decrease as one gets older ${ }^{12,22}$. Age is not necessarily associated with an oral aesthetics negative perception, but with cognitive factors. It must be considered that the human aging process is generally followed by a greater susceptibility to chronic degenerative diseases. In this scenario, it is expected that oral health issues are still seen as less important or secondary ${ }^{25}$. It is also important to recognize that other aspects have been reported in the literature as associated with image self-perception. Older adults exposed to higher social interaction was associated with better self-esteem when compared to those with limited or reduced social activities ${ }^{27,28}$. When considering that $82.2 \%$ of our sample consisted of retired elderly, participation in social activities may have a beneficial influence on the participants' perception of self-image. However, this variable was not assessed, which might be a limitation of the present study.

In the present study, lack of access to professional oral care was associated with greater concern with dental aesthetics. There seems to be a lower predisposition to dental treatments among the elderly, especially regarding preventive strategies ${ }^{29,30}$. In addition, the cost of dental treatment should be considered when observing this association $^{31}$. It is particularly true for the majority of the elderly from Brazil, in which need of prosthesis reaches almost $70 \%$ of this population ${ }^{7}$. Access to dental treatment is directly related to educational level and income. A better educational level is usually associated with greater purchasing power, which results in more resources for investments in aesthetic treatments ${ }^{32}$. Unfortunately, the majority of the Brazilian elderly have a low level of education and income ${ }^{13}$. It should be emphasized that the majority of the population of the present study is from underprivileged strata in terms of education and is retired, which per se reduces income.

Moreover, oral health-related issues were also associated with concerns with appearance. The effect of most chronic oral diseases makes tooth extraction often the main treatment option, especially for the population from lower socioeconomical levels ${ }^{33}$. In the present study, elderly with at least one tooth present (dentate) were more concerned about their dental aesthetics. These individuals are probably more predisposed to dental treatments. In this sense, studies showed that edentulous elderly perceive less the need for dental treatment ${ }^{34}$ and present a better oral health-related quality of life $^{35}$ in comparison to elderly with teeth. This is especially true due to the presence of dentures, that, in one way or another, solve the aesthetic concern. In addition, the process of adaptation, that comes with age should be taken into consideration and could be part of the explanation for such findings. Also, it should be emphasized that having natural teeth, as assessed in the present study, does not mean having healthy dentition or having a satisfactory oral rehabilitation.

In the present study, sex was not associated with greater concern with dental appearance. Although similar results can be observed in the literature ${ }^{32}$, female gender is generally more associated with oral aesthetics concerns. Several studies demonstrate that women are less satisfied with their smile and express a greater desire for dental aesthetic treatments ${ }^{12,24,36}$. For a long time, having certain appearance standards were the only possibility of social advancement for women in many cultures and, therefore, they were resigned to aesthetic impositions still perceived today ${ }^{37}$. 
This study is representative of the two cities from the Rio Grande do Sul state regarding socioeconomic status and sex, taking into consideration the probabilistic sample per cluster conducted in both cities. In this sense, educational level and gender distribution of participants were similar to those observed in the last national census ${ }^{13}$. Additionally, examiners were trained and calibrated to data collection by the same researcher, which increases its internal validity. On the other hand, this study has some limitations: the cross-sectional design, which does not allow the temporality assessment of concern with dental appearance and the exploratory variables. Additionally, the quality of prosthetic rehabilitation was not evaluated. The time between evaluations for both cities (from July/August 2016 to December 2018/January 2019) may also be faced as another limitation, and must be considered when interpreting the results of the present study. Despite the limitations, the study design allows data generalization for comparisons with other home-based studies with a representative sample.

It was concluded that concern with dental appearance was low among the elderly. Higher concern with dental appearance was observed at younger ages, in those without access to the dentist, and who presented at least one natural tooth. However, smoking exposure was not associated with concern with dental appearance. The use of and need for dental prosthesis was not associated with concern with dental appearance among the elderly.

\section{Acknowledgements}

This study was financed in part by the Coordenação de Aperfeiçoamento de Pessoal de Nível Superior - Brasil (CAPES) - Finance Code 001. All other funding was self-supported by the authors. The authors report no conflict of interest related to this study.

\section{REFERENCES}

1. Tourani S, Behzadifar M, Martini M, Aryankhesal A, Mirghaed MT, Salemiet M, et al. Health-related quality of life among healthy elderly Iranians: a systematic review and meta-analysis of the literature. Health Qual Life Outcomes. 2018 Jan;16(1):18. doi: 10.1186/s12955-018-0845-7.

2. Kassebaum NJ, Bernabé E, Dahiya M, Bhandari B, Murray CJ, Marcenes W. Global Burden of Severe Tooth Loss: A Systematic Review and Meta-analysis. J Dent Res. 2014 Jul;93(7 Suppl):20S-28S. doi: $10.1177 / 0022034514537828$.

3. van der Putten GJ, de Baat C, De Visschere L, Schols J. Poor oral health, a potential new geriatric syndrome. Gerodontology. 2014 Feb;31 Suppl 1:17-24. doi: 10.1111/ger.12086.

4. Moreira RS, Nico LS, Tomita NE, Ruiz T. [Oral health of Brazilian elderly: a systematic review of epidemiologic status and dental care access]. Cad Saude Publica. 2005;21(6):1665-75. doi: 10.1590/s0102-311×2005000600013. Portuguese.

5. Kossioni AE, Hajto-Bryk J, Maggi S, McKenna G, Petrovic M, Roller-Wirnsberger RE, et al. An Expert Opinion from the European College of Gerodontology and the European Geriatric Medicine Society: European Policy Recommendations on Oral Health in Older Adults. J Am Geriatr Soc. 2018 Mar;66(3):609-613. doi: 10.1111/jgs.15191.

6. Ribeiro CG, Cascaes AM, Silva AE, Seerig LM, Nascimento GG, Demarco FF. Edentulism, severe tooth loss and lack of functional dentition in elders: a study in southern Brazil. Braz Dent J. 2016;27(3):345-52. doi: 10.1590/0103-6440201600670. 
7. Azevedo JS, Azevedo MS, Oliveira LJC, Correa MB, Demarco FF. [Needs for dental prostheses and their use in elderly Brazilians according to the National Oral Health Survey (SBBrazil 2010): prevalence rates and associated factors]. Cad Saude Publica. 2017 Aug;33(8):e00054016. doi: 10.1590/0102-311X00054016. Portuguese.

8. Stenman U, Ahlqwist M, Björkelund C, Hakeberg M. Oral health-related quality of life--associations with oral health and conditions in Swedish 70-year-old individuals. Gerodontology. 2012 Jun;29(2):e440-6. doi: 10.1111/j.1741-2358.2011.00495.x.

9. Lajnert V, Pavičić DK, Gržić R, Pahor D, Kuis D, Simonić-Kocijan S, et al. Influences of age and maxillary anterior teeth status on patient's satisfaction with dental appearance and tooth colour. Gerodontology. 2012 Jun;29(2):e674-9. doi: 10.1111/j.1741-2358.2011.00543.x.

10. Bidinotto AB, Santos CM, Tôrres LH, de Sousa MD, Hugo FN, Hilgert JB. Change in Quality of Life and Its Association with Oral Health and Other Factors in Community-Dwelling Elderly Adults-A Prospective Cohort Study. J Am Geriatr Soc. 2016 Dec;64(12):2533-8. doi: 10.1111/jgs.14482.

11. Dalazen CE, Bomfim RA, De-Carli AD. Factors behind self-perceived need for dental treatment and prosthesis in Brazilian elderly people. Cien Saude Colet. 2018 Mar;23(3):945-52. doi: 10.1590/1413-81232018233.09682016.

12. Vilela EA, Martins AM, Barreto SM, Vargas AM, Ferreira RC. Association between self-rated oral appearance and the need for dental prostheses among elderly Brazilians. Braz Oral Res. 2013;27(3):203-10. doi: 10.1590/S1806-83242013005000010.

13. Ministry of Planning, Budget and Management. Brazilian Institute of Geography and Statistics - IBGE. [Demographic Census 2010: population characteristics and households - results of the universe]. Rio de Janeiro: IBGE; 2011. Portuguese.

14. Ministry of Planning, Budget and Management. Brazilian Institute of Geography and Statistics - IBGE. [Human development Index, 2010]. Rio de Janeiro: IBGE; 2010. Portuguese.

15. Ministry of Health of Brazil. [Gini index of per capita household income-Rio Grande do Sul, 2010]. Brasília: Ministry of Health; 2010. Portuguese.

16. Liu Y. The relationship between lifestyle and self-reported oral health among American adults. Int Dent J. 2014 Feb;64(1):46-51. doi: 10.1111/idj.12061.

17. Stoffel LMB, Muniz FWMG, Colussi PRG, Rösing CK, Colussi EL. Nutritional assessment and associated factors in the elderly: apopulation-based cross-sectional study. Nutrition. 2018 Nov;55-56:104-10. doi: 10.1016/j.nut.2018.03.053.

18. Ministry of Health of Brazil. [Primary Health Care Assessment Instrument Manual: PCATool-Brasil]. Brasília: Ministry of Health; 2010 [access 2019 May 4]. Available from: http://189.28.128.100/dab/ docs/publicacoes/geral/manual_instrumento_avaliacao.pdf. Portuguese.

19. Colaço J, Muniz FWMG, Peron D, Marostega MG, Dias JJ, Rosing CK, et al. Oral health-related quality of life and associated factors in the elderly: a population-based cross-sectional study. Cien Saude Colet 2020. [Access 2020 Jun 17]. Available from: http://www.cienciaesaudecoletiva.com.br/ artigos/oral-healthrelated-quality-of-life-and-associated-factors-in-the-elderly-a-populationbasedcrosssectional-study/17160.

20. Furtado GE, Sousa ML, Barbosa TS, Wada RS, Martínez-Mier EA, Almeida ME. [Perceptions of dental fluorosis and evaluation of agreement between parents and children: validation of a questionnaire]. Cad Saude Publica. 2012 Aug;28(8):1493-505. doi: 10.1590/s0102-311×2012000800008. Portuguese.

21. World Health Organization (WHO). WHO. Oral health surveys-basic methods. $4^{\text {th }}$ ed. Geneva: Switzerland; 1997.

22. Wulfman C, Tezenas du Montcel S, Jonas P, Fattouh J, Rignon-Bret C. Aesthetic demand of French seniors: a large-scale study. Gerodontology. 2010;27(4):266-71. doi: 10.1111/j.1741-2358.2009.00331.x 
23. Goulart MA, Condessa AM, Hilgert JB, Hugo FN, Celeste RK. Concerns about dental aesthetics are associated with oral health related quality of life in Southern Brazilian adults. Cien Saude Colet. 2018 Nov;23(11):3957-64. doi: 10.1590/1413-812320182311.24172016.

24. Lajnert V, Kovacevic Pavicic D, Pavlic A, Pokrajac-Bulian A, Spalj S. Smile Aesthetics Satisfaction Scale: development and validation of a new brief five-item measure of satisfaction with smile aesthetics in adults and the elderly. Int Dent J. 2018 Jun;68(3):162-70. doi: 10.1111/idj.12362.

25. Alkhatib MN, Holt R, Bedi R. Age and perception of dental appearance and tooth colour. Gerodontology. 2005 Mar;22(1):32-6. doi: 10.1111/j.1741-2358.2004.00045.x.

26. Nitschke I, Müller F. The impact of oral health on the quality of life in the elderly. Oral Health Prev Dent. 2004;2 Suppl 1:271-5.

27. Denissen JJ, Penke L, Schmitt DP, Van Aken MA. Self-esteem reactions to social interactions: evidence for sociometer mechanisms across days, people, and nations. J Pers Soc Psychol. 2008 Jul;95(1):181-96. doi: 10.1037/0022-3514.95.1.181.

28. Juth V, Smyth JM, Santuzzi AM. How do you feel? Self-esteem predicts affect, stress, social interaction, and symptom severity during daily life in patients with chronic illness. J Health Psychol. 2008 Oct;13(7):884-94. doi: 10.1177/1359105308095062

29. Wall TP, Brown LJ. Recent trends in dental visits and private dental insurance, 1989 and 1999. J Am Dent Assoc. 2003 May;134(5):621-7. doi: 10.14219/jada.archive.2003.0231.

30. Manski RJ, Hyde JS, Chen H, Moeller JF. Differences Among Older Adults in the Types of Dental Services Used in the United States. Inquiry. 2016 Jun;53:0046958016652523. doi: 10.1177/0046958016652523.

31. Maille G, Saliba-Serre B, Ferrandez AM, Ruquet M. Use of care and the oral health status of people aged 60 years and older in France: results from the National Health and Disability Survey. Clin Interv Aging. 2017 Jul;12:1159-66. doi: 10.2147/CIA.S135542.

32. Strajnić L, Bulatović D, Stančić I, Živković R. Self-perception and satisfaction with dental appearance and aesthetics with respect to patients' age, gender, and level of education. Srp Arh Celok Lek. 2016 Nov-Dec;144(11-12):580-9.

33. Elani HW, Harper S, Thomson WM, Espinoza IL, Mejia GC, Ju X, et al. Social inequalities in tooth loss: A multinational comparison. Community Dent Oral Epidemiol. 2017 Jun;45(3):266-74. doi: $10.1111 /$ cdoe. 12285 .

34. Hugo FN, Hilgert JB, de Sousa MaL, da Silva DD, Pucca GA. Correlates of partial tooth loss and edentulism in the Brazilian elderly. Community Dent Oral Epidemiol. 2007 Jun;35(3):224-32. doi: 10.1111/j.0301-5661.2007.00346.x.

35. de S Leao R, Maior JR, Pereira FC, Monteiro GQ, de Moraes SL. Impact of oral health and sociodemographic factors on quality of life: a cross-sectional Study. J Contemp Dent Pract. 2018 Apr;19(4):438-42

36. Xiaoxian Meng, Gilbert GH, Duncan RP, Heft MW. Satisfaction with dental appearance among diverse groups of dentate adults. J Aging Health. 2007 Oct;19(5):778-91. doi: 10.1177/0898264307304373.

37. Macia E, Duboz P, Chevé D. The paradox of impossible beauty: body changes and beauty practices in aging women. J Women Aging. 2015;27(2):174-87. doi: 10.1080/08952841.2014.929403. 